\title{
Nature-inspired solution for improving buildings environmental performance
}

\author{
H. Askari \& H. Taleb \\ Sustainable Design of the Built Environment, \\ Faculty of Engineering \& IT, The British University in Dubai, UAE
}

\begin{abstract}
Biomimicry is an approach to innovation that seeks sustainable solutions to human challenges by emulating nature's time-tested patterns and strategies. This paper will show how biomimicry can be implemented in the built environment to improve its current situation in terms of sustainability and to reduce energy consumption by examining the current situation of a chosen location. It will then compare the improvements proposed through biomimicry by analysing the suggested design methods. Black-lip oysters were chosen as the inspirational concept to be implemented in this study, as they have been very important creatures for the economy in the gulf region due to their pearl production. The built environment location chosen is 'The Women's Museum', a well-known cultural project located in the old area of Dubai. It is an area in which pearl diving and pearl trading was once the most important source of income. In this study, new design methods are suggested for the environmental strategies focused on and based on the use of black-lip oysters. The proposed design methods are then studied and examined through simulation software analysis, showing and discussing the differences each design method will make on the specified location. The examined built environment in this study can then be used as a model in order to improve the area on an urban level through biomimicry in the future.
\end{abstract}

Keywords: biomimicry, sustainable built environment, energy efficiency, sustainability, UAE.

\section{Introduction}

Biomimicry is a science in which solutions for human activities are given by adapting strategies from nature as well as the behaviour of natural elements in the 
world. Human activities and practices over the past few decades have affected nature and the environment negatively due to industrialisation and development. Nature-inspired and -oriented inventions can help the human to solve problems or guide them into a better life and to consider the other creatures on earth as part of biomimicry as well [1]. This research paper shows how biomimicry can be implemented for the built environment to improve its current situation in terms of both sustainability and reducing energy consumption. This is done by examining the current situation of a chosen part of the built environment. It will then compare the improvements proposed through biomimicry by analysing the suggested design methods.

While searching for inspiration for this study, the main concern was to choose a natural concept that had been of significant importance in people's lives, but due to circumstances, people have become ignorant to nowadays. In the past, before the discovery of oil in the gulf region, the economy of the area largely depended on pearl trading. Divers used to go on pearl diving trips and traders ran pearl trading businesses and distributed them to other parts of the world. The discovery of oil, as well as of cultured and artificial pearls, negatively affected this profession in the United Arab Emirates (UAE). Thus, over time, people started to ignore the pearl-related profession, as the low income was not a sufficient reward for the danger and the difficulties pearl divers faced in their daily lives [2].

\section{Methodology}

This study is based on studying the current situation of a built environment, by visiting different sites and by making calculations using Ecotect simulation software. Our proposals are based on a comparison of the situation, before and after. Some other strategies were suggested, however, after obtaining the results from the simulation software, and it was concluded that, due to their effects, they would not be feasible for implementation. Three main lessons were attained and studied, as shown in Table 1.

Table 1: Summary of the lessons learnt and suggested strategies.

\begin{tabular}{|l|l|l|}
\hline Lesson in oyster & Suggested strategies & Detailed strategy \\
\hline Shell structure & Proposed shading device & $\begin{array}{l}\text { 'Twisty' based on } \\
\text { Sunbrella fabrics }\end{array}$ \\
\hline $\begin{array}{l}\text { Light reflection of } \\
\text { pearl }\end{array}$ & $\begin{array}{l}\text { Solar radiation reflected } \\
\text { from building }\end{array}$ & $\begin{array}{l}\text { Dynamic movable } \\
\text { louvers for glass facade }\end{array}$ \\
\hline $\begin{array}{l}\text { Shell reaction to the } \\
\text { heat gain }\end{array}$ & $\begin{array}{l}\text { Protect the building } \\
\text { envelope from heat gain }\end{array}$ & Double-glazed windows \\
\hline
\end{tabular}

\section{Natural concept anatomy and environmental facts}

Black-lip oysters were chosen as the inspirational concept to be implemented in this study. The reason for this is the economic importance in the region they have exhibited in the past. Even though there are different types of oysters, most have the same body organs with similar functions. Black-lip oysters (Pinctada 
Margaritifera) are often found in areas with a hot climate. They live in the bottom of the sea, in reef habitats, and their life and the quality of pearl production depends on water temperature, water salt, $\mathrm{PH}$ and the amount of available oxygen in the water. The built environment solutions are extracted from the anatomy of the black-lip oysters, as well as their environmental factors. Natural pearls are the reaction of oysters towards having irritants entering their body. When a grain of sand gets caught inside the mollusc, it produces a very thin nacre layer $(90 \%$ of which is calcium carbonate) to surround the object and protect itself. The mollusc keeps making tissue nacre layers above each other until the pearl is formed over almost seven years. In nature, stress conditions affect the quality of pearls produced. Rapid changes in temperature, salt, oxygen and food, along with any other environmental factor, will cause stress to these bivalves, leading to poor quality pearls. There are some other creatures that share the same habitat as oysters. When the oyster's habitat is overpopulated with other creatures, oysters will face a dangerous situation as they will be competing over food and oxygen available in the water, resulting in stress and poor pearl quality. Oyster shells vary in shape and colour depending on their categories, but all will have an uneven texture to their shells. Shells are the main part exposed to the outer environment all the time and their main duty is to protect soft body organs. When the shells open, the required food and oxygen is allowed to enter for respiration and feeding purposes. Mantels contain all the soft body organs inside them. They are located between the hard shell and all the other soft organs. They ensure the growth of valves in the shell. Each oyster has two symmetrical gills, which filter water for feeding and respiration by allowing small particles through, making it possible for them to be digested (plankton smaller than $2 \mathrm{~mm}$ ) and reject the bigger ones. Each gill has a muscular and vascular part and the filtration system in the black-lip pearl oysters is more advanced than in other bivalves. The oyster's mouth is located at the end of these gills. Oysters move with the help of their foot; tongue-shaped organs, which have the ability to expand and contract, in order to give the ability to move in different directions. These feet are composed of a network of fibres, oriented to different sides. The reproduction process in pearl oysters occurs when they have gained excess energy. Fresh sea water and pollution-free water is very important for oysters, as polluted water affects their production, as well as causes disease. Fresh water contains more oxygen, which is important for respiration [3].

\section{Case study}

The built environment considered for applying the biomimicry solutions was intentionally chosen to be located in the old area of Dubai, as this was once the main active part of the region. Over time, they lost their significant features similar to the role of the pearl. These areas were built based on sustainable methods and, even though most of buildings are not sustainable anymore, they have retained some sustainable features. Therefore, providing a model to bring back sustainability based on current conditions in those areas will be encouraging for the surrounding environment. The area is typified by private commercial shops and the intention of this type of business is to earn money. The possibility of 
implementing improvements in the buildings will require initial costs, which would not be encouraged by such enterprises. On the other hand, the 'Women's Museum UAE' is well known for its cultural and educational activities and has a strong positive impact on its surroundings. The founder of the museum has already tried to implement more environmental friendly strategies where possible within the available possibilities. For the aforementioned reasons, providing a model in an effective built environment will have a stronger impact in influencing surroundings in the future.

\subsection{Women's Museum location}

The Women's Museum is in the Deira Gold Souq (known as old Dubai) next to the creek. The Gold Souq is one of the most active commercial areas in Dubai, having large numbers of retail shops and - due to its historical and traditional importance - big groups of tourists visit it. Dubai is covered with large deserts, however the humidity of the creek slightly affects the Gold Souq area, as it is surrounded from three sides by the creek (north, south and west). The museum is hidden in the narrow alleys of Gold Souq, surrounded by compact buildings.

\subsection{Women's Museum specifics}

The Women's Museum was opened in December 2012 and in a short time it was widely known, both nationally and internationally [4]. Improving the comfort level of such an important building with sustainable strategies will encourage a wider interest from the UAE community, as well as international guests, to think about adapting strategies to achieve comfort. The museum consists of three levels; the ground floor hosts a permanent exhibition, showcasing the history of the UAE through women. The second floor is dedicated to art works. The third floor has another exhibition room, as well as the 'Study Centre' in which 50 people can be accommodated at the same time. Different lectures and workshops are held in the study centre on a regular basis, along with documentary movie screenings [4]. The museum welcomes around 500 people a month and visitors are from different nationalities and age groups. VIPs from the government, and their guests, have been welcomed on a regular basis as well. Opening times for the museum are from $10 \mathrm{am}$ to $7 \mathrm{pm}$ every day and on Fridays they are open to from $5 \mathrm{pm}$ to $7 \mathrm{pm}$ only.

\section{Dubai geography and location}

Dubai, latitude 25.1 and longitude 55.2, is located on the costal line of UAE and is considered the second largest emirate in the UAE [5]. Large and wide deserts are the main features of Dubai's land. It is also divided into two parts by a creek, one side being named Deira and the other Bur Dubai. Dubai is a fast-growing city with huge projects under construction, which is reducing the empty desert land. Dubai and the UAE are considered as hot, dry areas due their desert landscapes. The temperature is very high during the summer (up to $45^{\circ} \mathrm{C}$ ). It drops to around $20^{\circ} \mathrm{C}$ in winter. The rainfall average is very low and it is almost dry over the year. 
Coastal lines are considered humid areas in which humidity can reach up to $90 \%$. Wind speed is very low and the direction is from the north, west and south most of the time [6]. It is not a windy city; the average wind velocity only varies between $0 \mathrm{~m} / \mathrm{s}$ to $7 \mathrm{~m} / \mathrm{s}$ and its direction varies in different directions. The relative humidity varies between dry and very humid in Dubai. Humidity is highest in the coastal areas at $90 \%$ and as you move away from the sea it gets drier and drops to below $50 \%$. The museum is located next to the creek, so humidity has a large impact on the environment there.

\section{Design methods}

In this section, the given design strategies are inspired by the black-lip oysters that are discussed here. For each strategy, the link is shown and an analysis of the implementation of each strategy is given. The analysis obtained from Ecotect below shows the solar exposure of the museum during different times of the year. In all seasons, the rooftop is the largest area to gain direct solar radiation (Fig. 1).

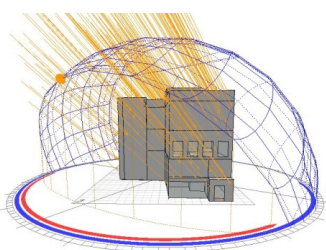

1 pm January

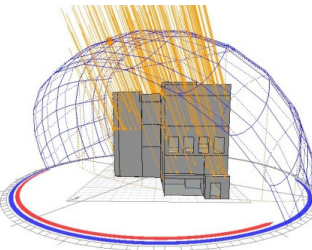

1 pm April

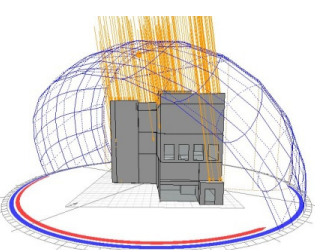

1pm July

Figure 1: Solar radiation on the museum.

Fig. 2 shows shadow during different seasons of the year within the neighbouring buildings. In January, there is a good amount of shadow on the north east, but at other times this amount is much reduced.
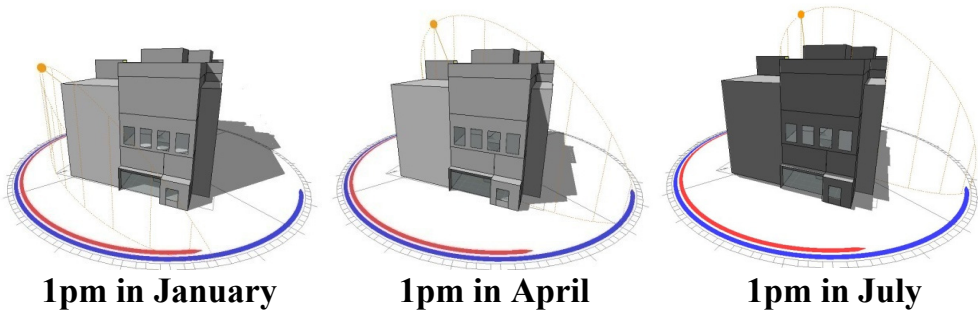

Figure 2: Shadow effect on the museum.

From the above analysis obtained from Ecotect, the area exposed to solar radiation is more on the rooftop and, therefore, needs protection. Even though the rooftop area is not currently being used, it is intended to function in the future for 
welcoming more guests and hosting activities [4]. Moreover, this amount of exposure to solar radiation is affecting the lower floors by gaining heat inside the building. Applying good shading strategies will help by blocking the uncomfortable solar radiation and providing a space, which can be utilised for different purposes. Also, to prevent heat gain to the lower grounds, improving insulation materials on the rooftop is also required.

Referring back to environmental facts from oysters, shells are the key, exposed to the outer environment all the time. Their main duty is to protect soft body organs. When the shell opens, food and oxygen are allowed to enter for respiration and feeding purposes.

The proposed shading device is based on an award-winning design, which is named 'twisty' and is based on Sunbrella brand fabrics. The fabric panels are twisted for stability, as well as for the distribution of light and for changing its direction [7]. To profit more from this shading device, applying solar cells to the surface is suggested, which could raise the project budget significantly. The angle and rotation of each twist can be adjusted according to a number of clicks. Other than providing shade, it reflects and distributes light inside as well. Each side has a different a colour, depending on the rotation and the degree of light distribution. There is no specific size for these panels and the height and width of each panel can be customised depending on the available space.

Fig. 3 shows the shadow pattern that will be produced by the twisting 'sunbrellas' when the panels are not twisted.

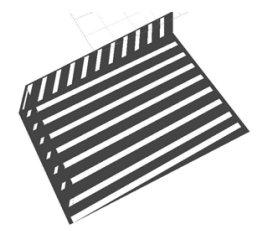

Figure 3: Sunbrella shadow effect on surface.

The following illustrations obtained by Ecotect analysis show the improved shading on the building for the rooftop area.

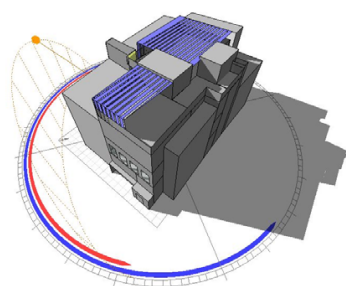

$1 p m$ in January

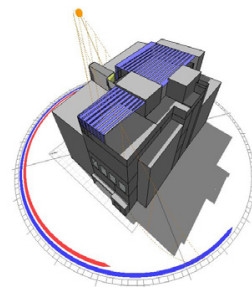

1pm in April

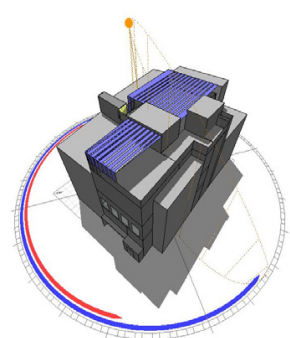

$1 p m$ in July

Figure 4: Shadow performance of shading devices. 
As seen above, there is a significant amount of shadow provided by the twisting sunbrellas. The proposed sunbrellas will start from the lift room wall and continue to the end. The height will be $3 \mathrm{~m}-$ similar to the height of the lift room. This height was considered so as not to exceed the height of the lift room, allowing it to benefit from natural ventilation.

Most of the HVAC system, as well as the water tank and other appliances, occupy an area at the back. Providing shadow for these systems will protect them and reflect any solar radiation that may be hitting them. Fig. 5 shows the solar radiation reflected by the sunbrellas.

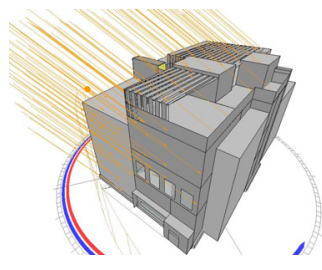

$1 p m$ in January

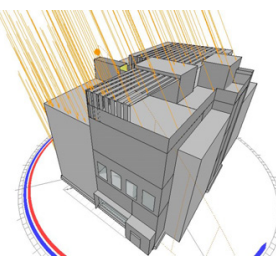

$1 p m$ in April

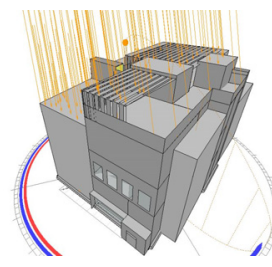

$1 p m$ in July

Figure 5: Solar radiation performance.

Overall, these sunbrella shading devices were adapted from oyster shells to protect the under parts against the outdoor environment. As examined and expressed earlier, the strategy is a successful method to create shadow.

\subsection{Daylight factors}

In the natural concept, the pearl quality is dependent on how much light they reflect. Since the pearl is formed from many layers, when light hits the surface, some layers absorb and some reflect.

Extrapolating from this environmental fact, the importance of reflecting or blocking extra and unwanted solar radiation can be concluded.

The indicated area on the plan is a space open to three levels of the building and is one of the ways to gain natural light inside. This glass facade is oriented to the south, which gets direct sunlight.

The museum has valuable historical items on display, as well as original artwork. Strong sunlight will cause damages to these items and it is crucial to be able to control the light entering the building. According to Professor Ghubash, founder of the Women's Museum, closing this shaft is not a good option, this area - even though it is small - is very important for the psychology of the space. Also, in the ground floor exhibition area, only two spaces allow natural light into the building. Thus, controlling the amount of light that enters at specific times will help improve the quality of the indoor environment. Since the building is located in a compact area, the surrounding buildings act as side barriers for radiation and protect the museum against them, as shown in Fig. 7. The only exposed area from the side is this glass facade. 


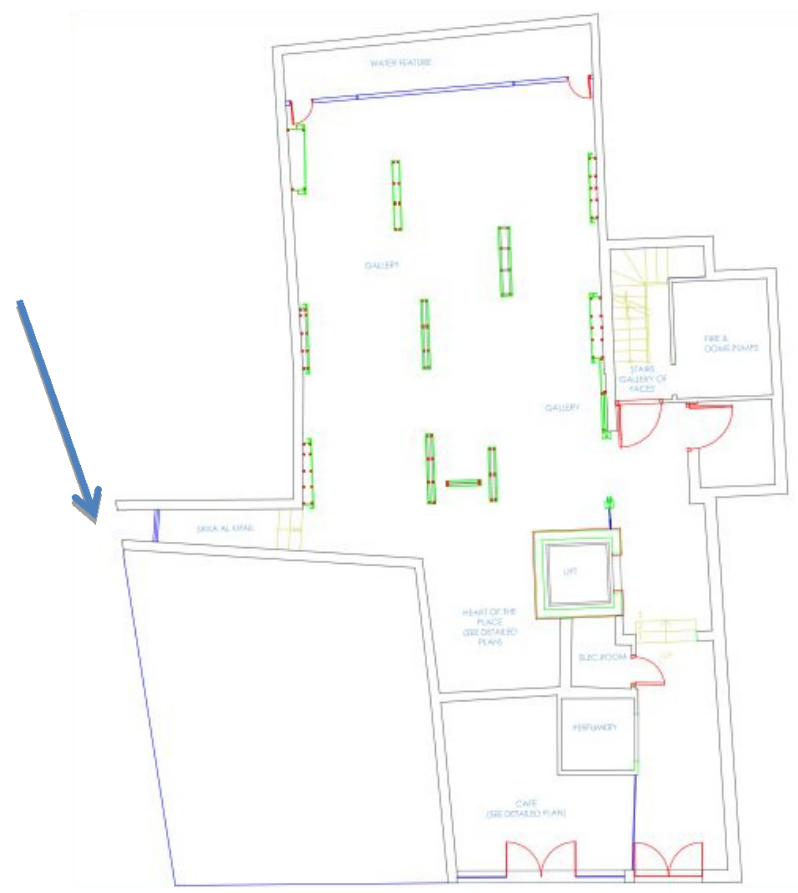

Figure 6: Glass area.

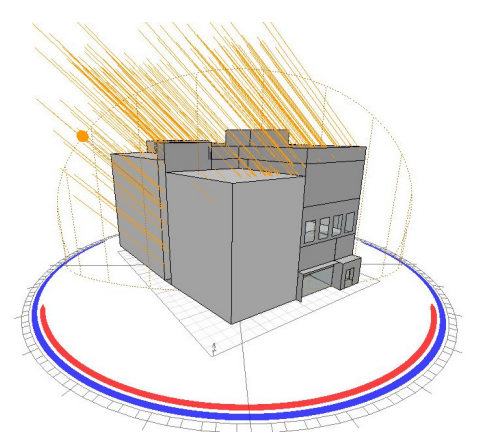

Figure 7: Solar radiation blocked by other buildings.

Fig. 8 shows the daylight factor analysis obtained from Ecotects, showing indoor illuminance for this area. It starts at around $80 \%$ and ranges to around $58 \%$. This is extremely high for any type of functioning space and also causes glare. Also, since the area is oriented to the south, heat gain from solar radiation is occurring as well. 


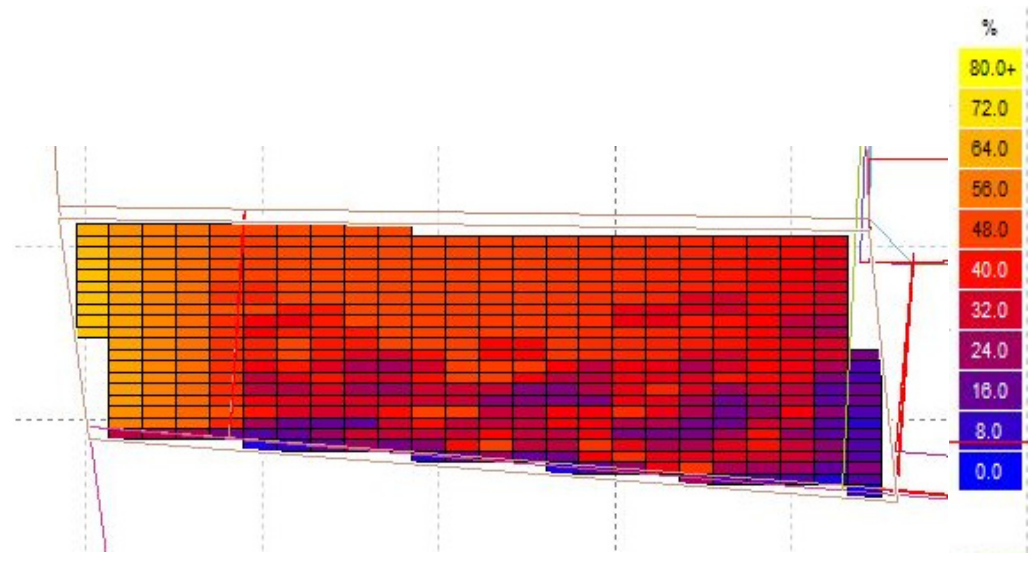

Figure 8: Daylight factor.

Applying movable louvres can improve the space. By using them, sun radiation can be blocked, reflected or allowed to enter the building based on the time of the day and the requirements of the space. Doing this will mean that beneficial light will still be entering the building and the displayed items in the galleries will be protected, as well as benefiting from the space, and it will make the small display area unaffected by glare. They can be positioned straight, to block all light from a specific panel when the sun radiation is hitting directly into a specific height (afternoons 1-3 pm) or can be positioned 90 degrees from the top view just to make small lines. This position will allow maximum solar gain, which is recommended in the morning for this space. Fig. 9 shows the results for the daylight factors after applying louvres as shading devices for this area. As it is shown, daylight factors are much improved and mostly to $18 \%$ or a little higher near the windows. This shows significant improvement in decreasing the extra daylight. Due to the flexibility of the louvres, they can all be opened to allow in maximum light in cloudy conditions or be fully closed on a particular area of the glass to block direct light.

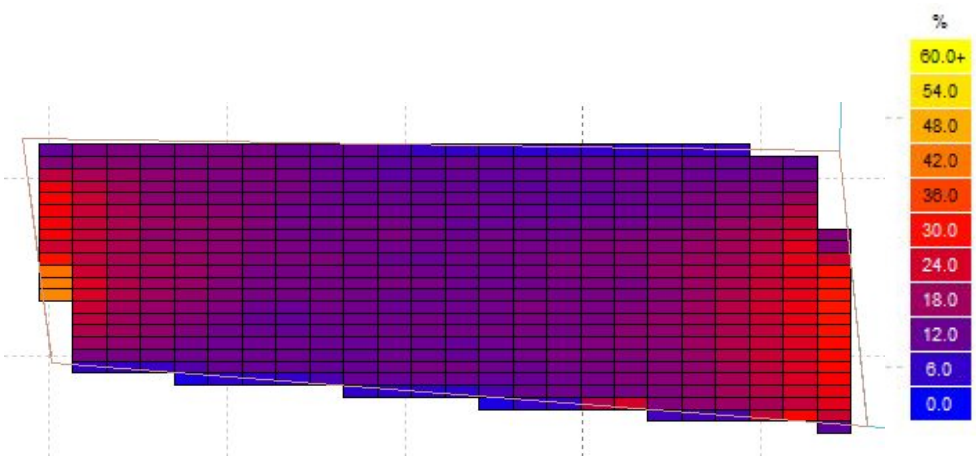

Figure 9: Improvements in daylight factors. 
The museum itself is designed in a way that implements the strategy of allowing required light to enter, based on floors and function. The library on the third floor gets a good amount of the light it needs. Moving to the lower floors, the amount of light is reduced on the ground floor, as explained earlier, because of original and historical artefacts. Therefore, the minimum light required and lighting in the exhibition is done through artificially controlled lighting (Fig. 10). However, if the artefacts were moved or changes happened to the gallery, then the amount of daylight could be enhanced by applying light shelves or other strategies.

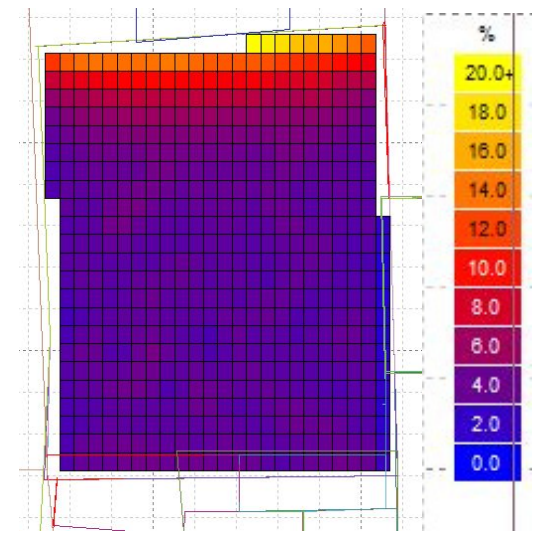

Figure 10: Daylight factors before applying reflectors to the ground floor.

\subsection{Building envelope}

Oysters can adapt to hot conditions of $35^{\circ} \mathrm{C}$, which affect their mechanism and can cause damage to the shell's function. When it is too hot, the shells will stay open and protection to the inner part will be lost. In the built environment, the amount of heat gain affects the comfort of people and, in turn, their productivity. Dubai is located in a hot arid area and the building envelope is a very important factor in enhancing the interior environment.

If the building is not sealed properly or the materials used in the construction have a high $U$ value, this will result in heat gain in the interior environment, which is not desirable in Dubai. The type of glazing used in the windows is a key factor as well.

The founder of the museum has already considered making the building more efficient from the early stages and implemented some aspects as much as possible based on the available suppliers. Fig. 11 shows solar exposure of the building over the entire year.

Heat gain can be caused by conduction and a high U-value in the material used in the construction. Referring to the natural concept of anatomy, when oysters open their shells they filter the water through their mantles and only get what they need (oxygen and small planktons). The implemented double-glazed windows act in the same way, filtering out the heat and letting light in. 


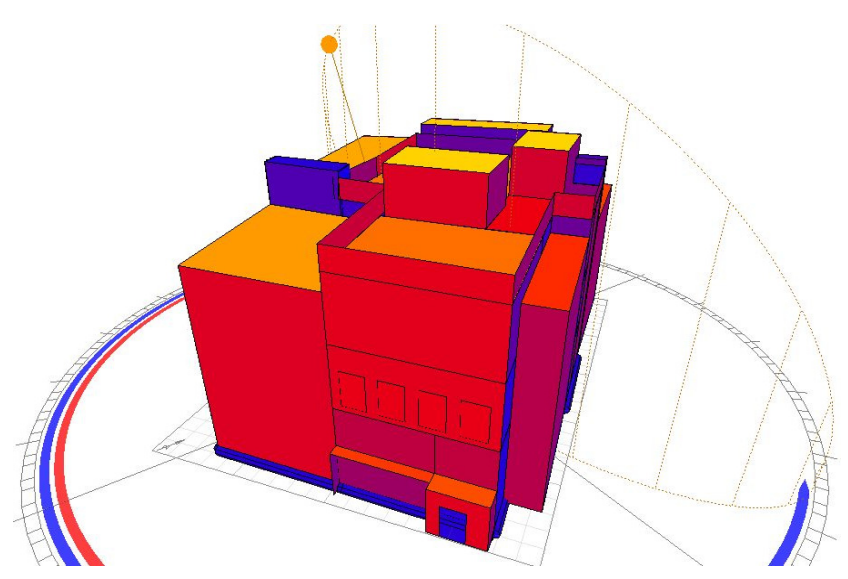

Figure 11: Solar exposure.

\section{Conclusion}

In conclusion, improving the old and historical areas of Dubai to achieve a more comfortable environment, by adapting sustainable methods, is a critical point for Expo 2020. Since the historical areas and museums located in old Dubai will be a part of the event, this should be considered as well. This paper has provided strategies derived from the black-lip oyster's anatomy and its environmental factors in order to enhance comfort levels at the Women's Museum located in Deira, Gold Souq, Dubai, UAE. The first strategy outlines the application of a sunbrella shading device to the rooftop, examined by Ecotect analysis software. The results were encouraging for the application to the case study building. The second strategy proposed movable louvres for the glass façade, which is open on three levels of the museum. Based on Ecotect daylight factor analysis, this strategy was successful as well. There was another proposal to increasing daylight factors on the ground floor, applying light shelves; this was not applied as the diagram did not show improvement.

The third strategy improved the building envelope by changing the glass type used in the windows from single-glazing to double-glazing, thus reducing the cooling load required for the museum.

\section{Acknowledgements}

The author would like to thank all those who helped in this research, especially Professor Rafia Ghubash, founder of the Women's Museum, and the museum team for providing valuable information for this research. Moreover, the authors would like to thank "MUSTADAMA Ltd. Sustainable Solutions" in Masdar City, 
Abu Dhabi, for sponsoring this paper to be presented in the "Sustainable Development and Planning Conference" held in Istanbul in May 2015.

\section{References}

[1] Biomimicry institute (2007-2009). Case Studies [online]. Available at: http://www.biomimicryinstitute.org/case_studies.php [Accessed 18 October 2013].

[2] Ras Al Khaima Pearls (RAK) (2013). Our History: Nature, Culture \& Treaasure [online]. Available at: http://rakpearls.com/web/our-history/ [Accessed 7 October 2013].

[3] Sudagar \& Hajibeglou (2011). Propagation and Cultivation of Pearl Oyster. Iran: Gorgan University of Agricultural Sciences and Natural Resources.

[4] Ghubash. R. (2013). Women's Museum UAE. Women's Studies Centre, UAE.

[5] UAE Government. (2013). Seven Emirates Port let [online]. Available at: http://www.government.ae/en/web/guest/seven-emirates?p_p_id=Seven Emirates_WAR_SevenEmiratesPortlet_INSTANCE_F2Af\&p_p_lifecycle $=$ 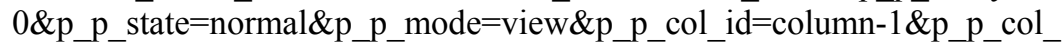 pos $=1 \& p \_p \_c o l \_c o u n t=2[\bar{A} c c e s s e d 11$ November 2013$]$.

[6] WeatherSpark (2013). Historical Weather for 2013 in Dubai, United Arab Emirates - WeatherSpark [online]. Available at:

https://weatherspark.com/history/32855/2013/Dubai-United-Arab-Emirates [Accessed 8 November 2013].

[7] Architizer (2013). Sunbrella [online]. Available at:

http://architizer.com/blog/architizer-and-sunbrella-announce-the-future-ofshade-competition-winners/ [Accessed 1 December 2013]. 